\title{
Práticas corporais na promoção de saúde e qualidade de vida: atuação entre Educação Física e Medicina na Escola Multicampi de Ciências Médicas do Rio Grande do Norte
}

\author{
I ${ }^{1}$ Marcel Alves Franco, ${ }^{2}$ Lilian Pereira da Silva, ${ }^{3}$ José Damião Rodrigues, \\ ${ }^{4}$ Milena de Oliveira Aguiar, ${ }^{5}$ Maria Isabel Brandão de Souza Mendes, \\ ${ }^{6}$ Iraquitan de Oliveira Caminha I
}

Resumo: Este artigo objetiva identificar a compreensão das práticas corporais dos alunos do curso de Medicina da Escola Multicampi de Ciências Médicas do Rio Grande do Norte e discutir sua realização no âmbito da Atenção Básica à Saúde. Por meio uma pesquisa documental de abordagem qualitativa, analisamos os 47 relatórios finais da disciplina Práticas Corporais na promoção de saúde e qualidade de vida, que ocorreu nos períodos 2017-1, 20172 e 2018-1. Com a análise dos documentos, foi possível identificar de que forma os alunos compreendiam o corpo e a saúde, ao mesmo tempo em que foram promovidas vivências que auxiliaram os alunos a superar preconceitos a respeito das práticas, ressaltando sua importância no âmbito da saúde, principalmente no que condiz a uma formação médica ampliada, à atuação na Atenção Básica, de forma a serem capazes de experienciar o próprio corpo e o do outro.

> Palavras-chave: Educação Física; Medicina; práticas corporais; saúde; Atenção Básica.

\author{
1 Universidade de Pernambuco. \\ Recife-PE, Universidade Federal \\ da Paraíba, João Pessoa-PB, Brasil \\ (macfranco1@gmail.com). \\ ORCID: 0000-0002-7468-2302 \\ ${ }^{2}$ Universidade Federal do Rio \\ Grande do Norte. Natal-RN, \\ Brasil (liliankelly10@hotmail.com). \\ ORCID: 0000-0002-4159-4090 \\ ${ }^{3}$ Universidade Federal da Paraíba. \\ João Pessoa-PB, Brasil (prof. \\ damiao@gmail.com). \\ ORCID: 0000-0003-2292-571X \\ ${ }^{4}$ Universidade Federal do Rio \\ Grande do Norte. Natal-RN, Brasil \\ (milenaguiar11@gmail.com). \\ ORCID: 0000-0001-6079-8980 \\ ${ }^{5}$ Universidade Federal do Rio \\ Grande do Norte. Natal-RN, \\ Brasil (isabelmendes@gmail.com). \\ ORCID: 0000-0002-9648-0007 \\ ${ }^{6}$ Universidade Federal da \\ Paraíba. João Pessoa-PB, Brasil \\ (iraquitancaminha@gmail.com). \\ ORCID: 0000-0003-0840-9727
}




\section{Introdução}

As bases para construção do Sistema Único de Saúde (SUS) se fortalecem desde a década de 70, com a criação do Centro Brasileiro de Estudos em Saúde (CEBES) e da Associação Brasileira de Saúde Coletiva (ABRASCO), que, juntamente com movimentos sociais e sindicatos, fortaleceram a Reforma Sanitária no âmbito da saúde. Nesse período, havia uma insatisfação da população de classes mais baixas, pois o sistema político da época era reflexo de uma distribuição de renda que favorecia apenas os mais ricos, de modo que os mais pobres não tinham acesso a infraestrutura, saneamento básico nem demais tipos de assistência à saúde (PAIM et al., 2011).

A promoção de saúde é uma das temáticas que merecem ser destacadas ao se tratar de assistência à saúde. Esta foi abordada em eventos como a primeira Conferência Internacional Sobre Cuidados Primários de Saúde, que aconteceu em 1978, em AlmaAta; a Conferência Internacional de Ottawa (OMS, 1986), em 1986; bem como a $8^{\text {a }}$ Conferência Nacional de Saúde, em 1986, no Brasil. Os encaminhamentos desses eventos propiciaram a reorientação dos serviços de saúde (MENDES, 2004).

Sendo também contemplada na Constituição Federal de 1988, a saúde passa a ser um direito de todos. Ao mesmo tempo, torna-se dever do Estado desenvolver açóes e projetos que venham suprir a demanda social em saúde e reprimir as iniquidades existentes (BRASIL, 1988). Nesse cenário, no ano de 1990, com a Lei 8.080, foi criado o SUS (BRASIL, 1990).

O SUS é um sistema gerenciado pelo Ministério da Saúde (MS) e é articulado com algumas tecnologias e ferramentas de suporte em saúde. Para termos uma compreensão da magnitude do SUS, podemos citar como exemplos: o Programa de Saúde da Família, criado em 1994 (BRASIL, 1997; VIANA; POZ, 2005), hodiernamente denominado Estratégia de Saúde da Família (ESF); em 2006, foi criada a Política Nacional de Promoção da Saúde (BRASIL, 2006a); em 2008, foram criados o Núcleo de Apoio à Saúde da Família (BRASIL, 2008) e os Centros de Apoio Psicossocial (CAPS); a Política Nacional de Práticas Integrativas e Complementares (BRASIL, 2006b), criada em 2006 e ampliada em 2015; e em 2011, e a Academia da Saúde (BRASIL, 2011).

O SUS, portanto, é um sistema que tem melhorado o acesso aos serviços de saúde dos brasileiros (PAIM et al., 2011), de forma a ampliar sua cobertura. Para seu funcionamento, é regido pelos princípios da universalidade, integralidade e 
equidade, o que significa que busca imprimir um sistema de saúde com qualidade (SUS, 2019). O primeiro princípio, a universalidade, é constitucional, ou seja, é a capacidade extensiva de ofertar os serviços para toda a populaçáo, independente das características sociais, pessoais e geográficas. Já a equidade retoma o seu caráter epistemológico, a busca por atender às necessidades dos usuários em consonância com suas especificidades, propondo uma redução das desigualdades e uma coerência social. Por fim, a integralidade se refere à capacidade do sistema em atender às demandas das pessoas, necessitando, portanto, de açóes conjuntas que mobilizam as políticas públicas, a atuação intersetorial e a qualidade de vida dos usuários (MATTOS, 2009). Para isso, o SUS depende da atuação de profissionais de diversas áreas que constituem a área da Saúde, a saber, Medicina, Odontologia, Fisioterapia, Enfermagem, Psicologia e, entre outras, a Educação Física.

A Educação Física passou a ser reconhecida como inserida na área da Saúde por volta de 1997, conforme a Resolução no 218 do Conselho Nacional de Saúde (CNS, 1997), em razão de um contexto de predominância das doenças crônicas não transmissíveis (DCNT). No entanto, foi apenas com a Portaria GM/MS no 154, de 24 de janeiro de 2008, que se legitimou o espaço da Educação Física na Atenção Básica, como profissional da ESF e do NASF-AB (BRASIL, 2008). A Educação Física passou então a ocupar o cenário da Saúde Coletiva.

Integrando-se ao âmbito da saúde desde o seu nível primário ao terciário, percebemos os objetivos da Educação Física envolvendo a promoção, a prevenção, a reabilitação e o tratamento das doenças, com ênfase nas DCNT. Além disso, outro cenário ocupado foi o da formação no ensino superior de outros profissionais de saúde, por sua contribuição com o conhecimento advindo das práticas corporais, atividade física e conhecimentos acerca do corpo e da saúde, como vem a ser o caso do bacharelado em Medicina, da Escola Multicampi de Ciências Médicas do Rio Grande do Norte (EMCM).

A EMCM, unidade da Universidade Federal do Rio Grande do Norte, atua na graduação em Medicina e nas residências multiprofissionais em Atenção Básica e de Saúde da Família. Sua proposta tem bases no compromisso social, na inovação de serviços no âmbito da saúde e na qualidade de vida no interior do estado. Por essa razão, os alunos são inseridos desde o primeiro semestre nas atividades da comunidade, nas unidades básicas de saúde. Estando a Educação Física inserida nesses espaços de formação e de atuação em saúde, em especial, na EMCM, 
questionamos como as práticas corporais podem impactar na formação médica e na sua percepção na Atenção Básica à Saúde. Com isso, objetivamos identificar a compreensão das práticas corporais dos alunos do curso de Medicina da EMCM e discutir sobre sua realização no âmbito da Atenção Básica à Saúde (ABS).

$\mathrm{O}$ presente artigo é organizado pelos seguintes tópicos: cenário da pesquisa, no qual apresentamos a EMCM, bem como a formação médica nessa instituição; procedimentos metodológicos, no qual são descritas as etapas e as formas de análise de nossa pesquisa; e práticas corporais na promoção de saúde e qualidade de vida, no qual são apresentados nossos achados da pesquisa e é feita a discussão acerca da temática.

\section{Cenário da pesquisa}

A EMCM possui sua sede em Caicó, cidade cujo censo de 2010 aponta possuir aproximadamente 63 mil habitantes, estimando, no ano de 2017, números próximos a 69 mil habitantes (IBGE, 2010). Em razão de sua faceta multicampi, o curso também conta com o apoio das cidades de Santa Cruz e de Currais Novos.

O processo de implantaçáo da EMCM teve início no ano de 2012, e suas atividades acadêmicas foram iniciadas no ano de 2014 (MELO et al., 2017). Como movimento promovido pela Universidade Federal do Rio Grande do Norte, seu objetivo é

[...] formar médicos inseridos na rede de saúde do interior do $\mathrm{RN}$, com vinculação à realidade social e de saúde da população, capazes de aliar qualificada formação técnico-científica com atitudes ético-humanísticas que os possibilitem trabalhar em equipe e impactar positivamente na realidade vigente (EMCM, 2017).

Nesse sentido, visando a formar profissionais qualificados, o esforço docente é realizar uma formação que valoriza a educação para a saúde da população, bem como estimular os futuros profissionais de saúde a perceberem os valores éticos e culturais de cada contexto, destacando-se as necessidades desses profissionais na zona rural (EMCM, 2017).

Como corpo docente, a EMCM possui, além dos profissionais médicos, profissionais de diversas áreas do conhecimento, tais como Biologia, Bioquímica, Fisioterapia, Enfermagem, Psicologia, Educação Física, Odontologia, Medicina Veterinária, Serviço Social, entre outros. Seu modelo de ensino é pautado em metodologias ativas e na integração ensino-serviço-comunidade. De acordo com Melo et al. (2017, p. 1335), a estrutura curricular da EMCM compreende duas 
fases sequenciais, sendo que "a primeira delas se refere aos Fundamentos da Prática Clínica (FPC), que acontece nos eixos de ensino tutorial, ensino de habilidades e ensino na comunidade, e inclui 31 módulos interdisciplinares nos quatro primeiros anos do curso"; no tocante à segunda fase, "refere-se ao Internato Médico (IM), que compreende os dois últimos anos da graduação".

De modo a atender lacunas de conhecimentos e ampliar a discussão visando a minimizar e a superar determinados "pré-conceitos" quanto às práticas corporais no âmbito da Atenção Básica, o módulo de cunho optativo Práticas Corporais na Promoção de Saúde e Qualidade de Vida buscou, por meio de uma abordagem interdisciplinar, realizar estudos, discutir métodos e técnicas corporais, com a finalidade de promoção de saúde para grupos especiais (hipertensos, diabéticos, idosos), além de promover vivências de diversas práticas para os alunos de Medicina experimentarem e poderem relatar suas impressóes a partir da experiência de si mesmos.

\section{Procedimentos metodológicos}

O módulo Práticas Corporais na Promoção de Saúde e Qualidade de Vida foi organizado da seguinte maneira:

1. Encontro de apresentação do professor/alunos(as) e conteúdo programático. Neste encontro, era feita a avaliaçáo diagnóstica para identificar o que de conhecimento acerca das práticas corporais os alunos possuíam, o que gostavam de praticar, o que entendiam sobre corpo, sobre saúde, e quais eram suas expectativas com o módulo. Além disso, foi um momento para apresentar os referenciais teóricos nos quais o professor se baseia para ministrar suas aulas e quando aborda tais conceitos (corpo, saúde, práticas corporais) e organizar a série de vivências a serem promovidas ao longo de cada encontro.

2. Como critério para a seleção das vivências, temos a condição do que o professor poderia oferecer para a turma (alongamento, atividades lúdicas, massagem, por exemplo), bem como o contato com outras pessoas que seriam convidadas para serem facilitadoras (yoga, ventosaterapia, por exemplo). Feita a seleção das práticas a serem vivenciadas, antes de cada encontro era disponibilizado um material didático, seja artigo científico ou manual técnico para os alunos conhecerem o contexto de cada prática, seus principais elementos constituintes e objetivos. 
3. Era realizado um encontro semanal, com duração de $1 \mathrm{~h} 30 \mathrm{~min}$. Mesmo com o material disponibilizado anteriormente, em cada encontro era promovida primeiro a vivência para, em seguida, ser feita a discussão. Tal estratégia foi elaborada de modo aos alunos terem alguma aproximação mínima com a parte teórica da prática, vivenciarem a prática com o próprio professor do módulo ou algum(a) facilitador(a) convidado(a), e, após a vivência, terem não somente a percepção teórica, mas as sensaçóes no corpo para discutirmos acerca dos impactos, benefícios, dificuldades, entre outras temáticas que forem surgindo em cada prática.

4. Ao final do módulo, o professor disponibiliza um modelo de relatório para os alunos cuja estrutura está apresentada no quadro 1.

\section{Quadro 1. Modelo de relatório elaborado para o módulo}

\begin{tabular}{|c|}
\hline Introdução \\
\hline $\begin{array}{l}\text { - Relatar as expectativas iniciais e os motivos para com o módulo. } \\
\text { - Primeiras impressóes quanto a abordagem escolhida pelo professor para o módulo. } \\
\text { - Relatar anseios, receios, sensaçóes de desafios, etc. quanto a perceber as práticas corporais como } \\
\text { possibilidade de recomendaçáo/atuaçáo de terapêutica médica. }\end{array}$ \\
\hline Desenvolvimento I \\
\hline $\begin{array}{l}\text { - Relatar impressões pessoais sobre os textos discutidos. } \\
\text { - Fazer uso dos textos para argumentar sua compreensão de corpo e de práticas corporais. } \\
\text { - Fazer uso dos textos para argumentar como houve a ampliação dessa compreensão, se houve. } \\
\text { - Relatar impressões pessoais sobre as práticas vivenciadas (yoga, massagem, atividades lúdicas, } \\
\text { relaxamento). } \\
\text { - Fazer ligação com os textos e o tema do módulo "práticas corporais na promoção de saúde e qualidade } \\
\text { de vida”. }\end{array}$ \\
\hline Desenvolvimento II \\
\hline $\begin{array}{l}\text { - Relatar como foi a elaboração da vivência, qual grupo de pessoas participou (familiares, colegas } \\
\text { de turma, comunidade) e descrever abordagem que utilizaram e as impressóes das pessoas que } \\
\text { vivenciaram. }\end{array}$ \\
\hline Consideraçôes finais \\
\hline $\begin{array}{l}\text { - Relatar impressóes pessoais sobre o módulo como um todo. } \\
\text { - Apontar contribuiçóes do módulo no tocante à percepçáo de corpo e saúde na formaçáo médica. } \\
\text { - Apontar sugestôes/críticas para melhora do módulo na formação médica. }\end{array}$ \\
\hline
\end{tabular}

Fonte: elaboração própria. 
Como o curso possibilita imersão dos alunos na comunidade desde o primeiro semestre, e de modo mais efetivo, na "Vivência na Comunidade", componente curricular obrigatório que promove um mês de imersão dos alunos nos serviços em saúde, aproveitamos a oportunidade para que os alunos que já estariam nos serviços enquanto duplas pudessem promovê-lo juntos. Outros(as) alunos(as), por terem duplas nos serviços que não cursaram o módulo, tiveram o auxílio na realização das práticas, porém elaboraram seus relatórios individualmente. Outros(as) alunos(as) já teriam passado do momento da vivência; para estes casos, foi organizado um momento para a promoção de práticas conduzidas por eles(as) mesmos(as) na própria instituição, de modo gratuito e acessível à comunidade interna e externa, o que promoveu relatórios elaborados, no máximo, em trios.

A partir desses relatórios finais, realizamos uma pesquisa documental (GIL, 2002), cuja abordagem é qualitativa. Sobre a abordagem qualitativa, de acordo com Minayo (2009), buscamos interpretar os sentidos e significados atribuídos ao fenômeno investigado pelos sujeitos que estão diretamente relacionados com ele. Por se tratar de uma pesquisa documental, tratamos de fontes que ainda não receberam tratamento analítico da seguinte forma:
a) determinação dos objetivos; b) elaboração do plano de trabalho; c) identificação das fontes; d) localização das fontes e obtenção do material; e) tratamento dos dados; f) confecção das fichas e redação do trabalho; g) construçáo lógica e redação do trabalho" (GIL, 2002, p. 87).

Foram analisados 47 relatórios que correspondem às três turmas que cursaram o módulo, cada uma nos respectivos períodos 2017-1, 2017-2 e 2018-1. A turma 2017-1 era composta por alunos 24 alunos; a turma 2017.2, por 14 alunos; e a turma 2018.1, por 17 alunos. Para preservar a identificação dos sujeitos, as turmas foram identificadas com as letras $\mathrm{A}, \mathrm{B}$ e $\mathrm{C}$, ao relatório atribuímos um número correspondente.

$\mathrm{Na}$ análise dos relatórios, nosso olhar foi conduzido por unidades temáticas, a saber: Saúde; Corpo; Corpo e Saúde (unidade que representa associaçáo feita pelos alunos); Prática Corporal/Atividade Física/Exercício Físico; Metodologia/Ensino; Práticas Corporais e Saúde (unidade que representa associação feita pelos alunos).

Com a leitura analítica dos relatórios, foram construídas fichas que discriminam: a identificação do relatório; o ano/semestre no qual o relatório foi produzido; a confirmação ou náo por parte dos(as) alunos(as) se houve mudança na percepção do corpo e da saúde; a identificação acerca do que mudou na compreensão de corpo 
e de saúde; a percepção dos(as) alunos(as) sobre a mudança de seus conceitos; e a importância das práticas corporais na Atenção Básica. Neste artigo, em especial, destacamos que foram utilizadas as fichas de compreensão de saúde, de mudança na compreensão dos(as) alunos(as) e da importância das práticas corporais.

\section{Práticas corporais na qualidade de vida e na promoção de saúde}

No início do módulo, a expressão "práticas corporais" parecia ser novidade para alguns dos(as) alunos(as). A confusão foi identificada devido às aproximaçóes feitas entre os conceitos de atividade física e de práticas corporais, que muitas vezes não são claros mesmo em documentos oficiais. Como, por exemplo, na Portaria no154, de 2008, a qual cria o NASF, temos compreensão de que as práticas corporais/ atividade física são

[...] açóes que propiciem a melhoria da qualidade de vida da população, a redução dos
agravos e dos danos decorrentes das doenças não transmissíveis, que favoreçam a redução
do consumo de medicamentos, que favoreçam a formaçáo de redes de suporte social e
que possibilitem a participação ativa dos usuários na elaboraçáo de diferentes projetos
terapêuticos (BRASIL, 2008).

Por essa razão, foram trabalhados alguns materiais para formularmos os conceitos de atividade física, práticas corporais e exercícios físicos, esclarecendo suas aproximaçóes e distanciamentos. Para essa discussão, utilizamos de alguns referenciais. São eles: Vilarta (2007), Brasil (1995), Melo, Antunes e Schneider (2005) e Carmo Júnior (1999).

Em Vilarta (2007), foram utilizados, em especial, dois capítulos. No primeiro, a atividade física encontra-se relacionada à prevenção e ao controle de doenças crônicas náo transmissíveis, de riscos e de mortalidade, além de representar promoçáo de saúde e em contraste das consequências da inatividade física, ou seja, "uma causa importante de reduzida qualidade de vida e morte prematura nas sociedades contemporâneas, particularmente nos países industrializados" (MANTOVANI; FORTI, 2007, p. 13).

No segundo referencial, Oliveira (2007), a atividade física também aparece como forma de prevenção quanto à hipertensão e sua manutenção, indicando que pessoas sedentárias possuem $30 \%$ de chance a mais de desenvolver tal condição. Nesse estudo, em especial, começamos a abrir algumas possibilidades de atuação para além da atividade física, pois consta a questão de relaxamento, como podemos 
perceber quando o autor destaca as orientaçóes da $V$ Diretrizes Brasileiras de Hipertensão de 2006: "o tratamento da hipertensão arterial deve incluir medidas não medicamentosas de controle da pressão arterial, dentre as quais destacam-se a realização regular de exercícios físicos aeróbios e o treinamento em relaxamento" (OLIVEIRA, 2007, p. 106).

No documento Orientaçóes básicas sobre atividade física e saúde para profissionais da educação e de saúde (BRASIL, 1995), em especial, no capítulo produzido por Silva (1995, p. 39), nos deparamos com a seguinte compreensão de atividade física:

A atividade física é a possibilidade de reencontro do homem consigo mesmo, pois através dela ele exprime a sua corporeidade, e nesta, a expressão de sua relação com o ecossistema em que está inserido, refletindo-se em sua expressão corporal e em seu comportamento todas as facilitaçôes, dificuldades, angústias, tensões e adaptaçôes impostas pela vida de relaçáo tanto na família quanto no trabalho ou em outros segmentos da vida social.

Interpretamos que tal compreensão de atividade física extrapola as limitaçôes da dimensáo biológica do corpo, uma vez que leva em consideração as emoçóes, sensaçôes, sentimentos, as relaçôes sociais e o ecossistema. Ao mesmo tempo, Silva (1995) nos traz a ideia de que a atividade física, como seu próprio nome sugere, está atrelada à condição física do ser humano, fazendo-se perceber por meio dos efeitos agudos e/ou crônicos.

As reflexóes de Silva (1995) acerca da atividade física, das prescriçôes, tanto por parte da Medicina quanto da Educação Física, precisam ser consideradas importantes, pois há uma forte associação construída com o tripé atividade física, aptidão física e saúde. Destacamos que, mesmo sendo um documento da década de 90, ainda é atual o discurso baseado neste tripé. Podemos citar Fraga (2006), que analisou os discursos que sustentam o Programa Agita São Paulo, criado em 1996, ativo até a presente data:

Além dos propalados benefícios fisiológicos (aptidão cardiorrespiratória, controle do peso, equilíbrio da pressão arterial, aumento da densidade óssea etc.) e psicológicos (redução do estresse, aumento da autoestima, diminuição da depressão etc.), a prática regular de atividades físicas pode influenciar positivamente nas escolhas/rejeiçôes individuais relacionadas ao fumo, álcool, uso de drogas, alimentação, práticas sexuais, além de contribuir para a diminuição dos índices de violência, evasão escolar, problemas familiares e qualidade do ar (FRAGA, 2006, p. 62-63).

Um discurso da atividade física como solução para diversas situaçôes. No estudo de Guedes (1995), sem aptidão física não se têm condiçôes de realizar atividades 
físicas de modo "adequado", o que, por sua vez, ocasionará um mal estado de saúde, com grandes possibilidades de desenvolvimento de doenças crônico-degenerativas e doenças crônicas não transmissíveis. Contudo, para Silva (1995), mesmo com a ideia de promoção de saúde, não se pode limitar a aptidão física e a atividade física em prescriçôes de cunho unicamente orgânico, não estão dissociadas das relaçôes sociais e demais manifestações culturais. Nesse sentido, as práticas corporais encontram seu espaço e importância para a saúde.

As práticas corporais, na perspectiva de Carmo Júnior (1999), consideram os aspectos culturais do movimento humano, mesmo os que se manifestam devido à necessidade de sobrevivência. A Educaçáo Física seria a área incumbida de apresentar o caminho de o ser humano conhecer sua dinâmica corporal. Na ontologia das práticas corporais, portanto, trata-se da corporeidade, da condiçáo de ser corpo. Com isso, passamos a compreender que "há mais ontologia e genealogia em praticar esportes, fazer ginástica, dançar, brincar, do que pressupôe a Educação Física construída pela ciência acadêmica sustentada pela razão" (CARMO JÚNIOR, 1999, p. 69).

Somando-se a essa perspectiva, Melo, Antunes e Schneider (2005) possuem o entendimento do valor simbólico e das significaçôes do movimento humano, no qual também se encontram inscritas a historicidade e a cultura, sem que estejam dissociadas da condição orgânica do corpo. O significado de práticas corporais, para Melo, Antunes e Schneider (2005, p. 115), remete a "expressóes concretas de formas de educação do corpo, de descobertas e vivência de prazeres, as quais são carregadas de valores, ideais de corpos, saúde, beleza e até mesmo de felicidade”. Nesse ínterim, é preciso trabalharmos na percepção de que no corpo não se separa organismo de simbolismo, objetividade de subjetividade, e atuar com as práticas corporais/atividades físicas é ter compreensão de que estas podem ser instrumentos didáticos, mas também terapêuticos, no contexto da atenção básica.

Sobre o viés terapêutico, o Ministério da Saúde (BRASIL, 2006) criou a Política Nacional de Práticas Integrativas e Complementares (PNPIC), a qual abarca um equivalente a 29 práticas e que se encontra em ampliação. Na origem dessa política as práticas norteadoras foram: fitoterapia e plantas medicinais, medicina tradicional chinesa, homeopatia, termalismo e crenoterapia e medicina antroposófica. Em virtude da expansão, conta-se com práticas como o yoga, biodança, arteterapia, meditação, osteopatia, reiki, shantala etc. Além disso, destacamos casos como a Política Estadual de Práticas Integrativas e Complementares do Estado do Rio 
Grande do Norte (RIO GRANDE DO NORTE, 2011), que traz outras práticas, tais como vivências lúdicas integrativas, medicina antroposófica, práticas corporais transdisciplinares, termalismo/crenoterapia, plantas medicinais, entre outros.

Com isso, para as vivências no módulo, tivemos alonga mento, yoga, ventosaterapia, tai chi chuan, massoterapia, meditação, atividades lúdicas e hidroterapia, cuja descrição e dinâmica dessas práticas serão expostas juntamente com a percepção dos alunos por meio de seus relatos.

A proposta da vivência de alongamentos, por exemplo, objetivou a avaliação postural e promover o contato inicial entre os participantes do módulo. A ideia de se estudar a anatomia do corpo do outro, ao mesmo tempo em que se busca ler as histórias que estáo inscritas nele, compuseram parte da estratégia desta vivência.

O alongamento, segundo Geoffroy (2001), apresenta tipos diferentes: ativodinâmico, passivo, postura passiva, ativo-passivo, alongamento postural, sendo este último o foco de nossa vivência. Na interpretação de Geoffroy (2001), o alongamento, além de ter papel preventivo, no sentido de preparar a musculatura, regulando o tônus postural, contribui na consciência corporal, gestos técnicos e desempenho, na recuperação, ao mesmo tempo em que evita problemas tendinosos, musculares e articulares, permitindo

[...] melhor mobilidade, uma melhor flexibilidade [...], desenvolvem uma determinada amplitude de movimento. [...], se opóem à rigidez [...], mantêm e melhoram a extensibilidade muscular e a mobilidade articular. [...], intervêm no reequilíbrio dos problemas morfológicos, na correção da postura [...], tem papel antiestresse e permitem a obtenção do bem-estar (GEOFFROY, 2001, p. 16).

Além disso, percebemos em sala que: "a realização de um simples alongamento em grupo pode significar um momento de união e fortalecimento de laços entre os profissionais da equipe (A4)".

Para com a vivência do yoga, utilizamos um manual de Hatha Yoga (TACCOLINI, 2004) e os estudos de Barros et al. (2014) e de Pinheiro et al. (2007) como material para a discussão. O yoga é uma prática cuja tradição é indiana e, por isso, apresenta proximidades com a medicina ayurveda. Na definição de Barros et al.(2014, p. 1306), o yoga representa "um conjunto de práticas psicoativas" que, além de ser recomendada pela OMS, foi inserida no SUS por meio da Portaria no 719, de 7 de abril de 2011 (BRASIL, 2011), e é reconhecida como uma das práticas integrativas e complementares em saúde. 
No decorrer da aula, foi vivenciada a hathayoga, um modo específico da prática do yoga. No hathayoga, existem os ásanas, ou seja, "a posição firme e confortável (sthira sukham ásanam), [...] o acoplamento com técnicas respiratórias (pránáyáma), uma ação mental (localização da consciência e mentalizaçôes), contrações (bandhas) e mudrás (gestos)" (TACCOLINI, 2004, p. 7).

Para a discussão, Barros, Siegel e Moura et al. (2014) utilizaram do yoga como parte de um programa de promoção de saúde. Utilizando dessa prática para promover vivências para os alunos, estes relataram sobre a superação de preconceitos e conheceram alguns dos benefícios da prática:

A atividade prática da yoga proporcionou a ruptura de pensamentos já pré-estabelecidos, muitas vezes até preconceituosos, sobre tal modalidade corporal. Devido ao desconhecimento de seus princípios e até mesmo pela cultura curativa ocidental, pouco se esperava dessa prática, o que, no entanto, ao final, causou uma surpresa bastante agradável (B7).

A implementação de atividades que busquem uma revisitação ao eu interior não é apenas benéfica em termos pessoais, mas auxilia fortemente na estruturação emocional de indivíduos e, portanto, no seu fortalecimento frente a tratamentos crônicos ou invasivos, a exemplo da utilização do yoga como auxílio no tratamento do câncer (B3).

Permitiu o conhecimento sobre a existência de outras modalidades de yoga, possibilitando assim um afastamento do imaginário popular sobre a prática e a obtenção de uma nova mentalidade desvirtuada de preconceitos (C2).

Por sua vez, a ventosaterapia é uma prática criada há séculos, como nos assegura Cunha (1996), ao apontar o uso de ventosas por Hipócrates e o povo grego, no século IV. Os equipamentos utilizados variaram, ao longo da história, em sanguessugas, chifres de animais como o búfalo, cabaças, bambu, copos de vidro, copos acrílico e hastes com algum material inflamável na ponta para que se ateasse fogo ou uma pistola de sucção (CUNHA, 1996).

A ventosaterapia é comum em países como China, Coréia e Japão (CUNHA, 1996), e sua prática "produz o aumento dos glóbulos brancos, aumento das hemácias, melhora a ação anti-hemorrágica, torna o sangue relativamente alcalino e fortalece o sistema imunológico do nosso organismo, sendo um excelente método preventivo e terapêutico contra as doenças" (CUNHA, 1996, p. 55). Sobre a ventosaterapia no Brasil, Kim (2002) aponta que a maioria da população não tem compreensão dos usos ou dos efeitos terapêuticos. E, nessa premissa, podemos incluir os alunos do módulo: "inicialmente, eu era cética quanto à funcionalidade das práticas corporais como garantia da saúde. Apesar de reconhecer os benefícios do relaxamento, de 
buscar equilíbrio corporal e de algumas práticas como ventosas, apresentava uma mentalidade voltada para medicamentos" (A5).

Outra prática vivenciada foi o tai chi chuan. O estudo de Kasai et al. (2010) foi a base teórica da vivência, o qual contribuiu para uma significativa melhora nos termos de desempenho e queixas de memória em idosas com comprometimento cognitivo leve, por meio de um programa de seis meses de tai chi chuan.

O tai chi chuan é uma prática milenar e se iniciou como uma arte marcial. $\mathrm{Na}$ China, é encontrado como atividade física para população idosa em razão dos baixos impacto e velocidade, trabalhando o equilíbrio, a força muscular, a flexibilidade e o controle postural, o que vem a auxiliar também na prevenção de quedas, uma vez que "consiste em execuçóes de movimentos circulares suaves, associadas a exercícios de respiração, concentração e relaxamento" (KASAI et al, 2010, p. 41).

No contexto da sala de aula, os alunos relataram a vivência do tai chi chuan da seguinte forma:

Como outro momento capaz de fazer-me entender os limites do meu corpo, dos meus movimentos, da minha respiração e do meu estado de tensão, na medida em que esse último se expressava quando fazia os movimentos que tal prática corporal requeria (C2).

Gostei bastante do ambiente da prática com o som que estava sendo tocado no momento, deixando o ambiente com a sensaçáo de calma e boas energias. Ademais, vi que dentro do âmbito do campo de trabalho do médico, essa técnica pode ser usada para a melhora significativa da memória e da autopercepção da memória em idosos portadores de comprometimento cognitivo leve (C4).

Em outro momento, desenvolvemos a massoterapia. Com o estudo de Santos e Silva (2015) como base, discutimos sobre os benefícios dessa técnica para com o relaxamento dos usuários das unidades básicas de saúde na Bahia. Situando o contexto histórico da massoterapia, os autores apontam que diferentes registros sobre a origem da massoterapia podem ser encontrados em países como Grécia, Roma, China, Índia, Japão e Egito. Sua tradução, partindo do grego masso, significa amassar (SANTOS; SILVA, 2015). Não se tem com precisão o período de origem dessa prática. Todavia, por volta de 1913, Pehr Henrik Ling foi o responsável pela difusão da massagem como técnica, em especial, a massagem sueca (SANTOS; SILVA, 2015).

A massagem é uma técnica corporal que faz uso do toque. A função desse toque é despertar emoçôes positivas, reduzindo o estresse de forma natural, não medicamentosa (SANTOS; SILVA, 2015). Por esses e outros motivos, a massoterapia foi inserida no contexto de saúde brasileiro por meio do SUS: 
Oferecer a Medicina Alternativa gratuitamente para complementar a Medicina Tradicional no SUS (Sistema Único de Saúde) é uma excelente iniciativa, pois, as terapias não tratam apenas da doença, mas do paciente de maneira global. Seu tratamento é menos invasivo, o paciente consome menos remédios, relaxa o corpo como um todo, controla o estresse do dia a dia, diminui dores no corpo, permite mais disposição para tarefas diárias, colabora para o controle emocional, ajuda na prevençâo de doenças e proporciona a consciência corporal (SANTOS; SILVA, 2015, p. 214).

A massagem, nesse sentido, foi vivenciada de modo a nos fazer refletir acerca da saúde tanto em seus aspectos físicos como emocionais e psicológicos, além de promover autopercepção. A importância de se trabalhar com outras práticas, aquelas que se denominam holísticas, pode ser evidenciada no relatório A5: "a cada aula, meu olhar sobre as práticas complementares inseridas como oficiais nos serviços prestados à população foram melhorando e aos poucos me fizeram refletir sobre qual o profissional eu quero ser"; e no relatório B3:

A massagem, outra técnica introduzida a nós, uma das mais populares entre as práticas corporais tanto no âmbito da saúde como na sociedade, nos possibilitou o entendimento da importância do contato humano no ato de cuidar, o toque, mesmo realizado sem objetivo terapêutico, tem benefícios inestimáveis sobre o indivíduo, por fatos desde estar ali recebendo aquela atenção e cuidado até os efeitos que a técnica consegue obter.

A meditação foi outra prática vivenciada. Sendo uma técnica também muito antiga, na qual as pessoas buscam "permanecer sentadas com os olhos fechados exercitando a concentração" (MELO; ANTUNES; SCHNEIDER, 2005). A meditação foi inserida no SUS pela política de práticas integrativas e define-se da seguinte forma:

Prática mental individual que consiste em treinar a focalização da atenção de modo não analítico ou discriminativo, a diminuição do pensamento repetitivo e a reorientação cognitiva, promovendo alteraçôes favoráveis no humor e melhora no desempenho cognitivo, além de proporcionar maior integração entre mente, corpo e mundo exterior (BRASIL, 2018, p. 77).

A prática foi realizada em posição sentada ou deitada, cada um optando por aquela que oferecia mais conforto. Com duração inicial de 5 minutos, os alunos buscaram não se fixarem a um pensamento e se concentrarem no processo de equilíbrio do corpo e na respiração. No entendimento dos alunos, a meditação, bem como as outras práticas, também estão relacionadas ao prazer, como podemos observar no relatório $\mathrm{C} 7$ : 


\begin{abstract}
Conhecer práticas alternativas de relaxamento e interação mais profunda com o corpo é um incentivo para experimentar as práticas corporais enquanto movimento e também como exercício para a mente, tornando a prática dessas atividades - lúdicas, alternativas, meditação - prazerosa e promotora de bem-estar e saúde.
\end{abstract}

Essa dimensão de práticas com prazer, identificada no relato, corrobora o que Melo, Schneider e Antunes (2006, p. 30) asseguram: “é inegável que qualquer que seja a técnica praticada, elas proporcionam prazer e bem-estar para a grande maioria dos adeptos, pois fomentam modificaçôes químicas no organismo, as quais podem produzir essas sensaçôes corporais". Com isso, ampliamos as possibilidades de práticas para uma perspectiva que se não restringe a uma ou outra técnica, mas que envolve a dimensão da ludicidade.

A relação das atividades lúdicas com a saúde foi objeto de discussão da turma. Sendo regulamentadas na Política Estadual de Práticas Integrativas e Complementares do Rio Grande do Norte (2011) como vivências lúdicas integrativas, tomamos também como fundamento o estudo de Mendes e Medeiros (2010), que investigou as práticas inseridas no SUS, por meio do Programa Saúde da Família (PSF), nas unidades básicas de saúde da cidade de Natal/RN. Analisando as atividades em 34 unidades, as autoras perceberam "uma reorientação das práticas em saúde, que passam a pautar-se pelo princípio da integralidade, uma vez que se amplia o olhar sobre o processo de atenção à saúde, não se restringindo às práticas curativas" (MENDES; MEDEIROS, 2010, p. 36).

No estudo de Mendes e Medeiros (2010), foram identificadas as seguintes práticas: festas, passeios, caminhadas, artes manuais (crochê, bordado, pintura artesanato com materiais recicláveis, entre outras), atividades com idosos (hipertensos e diabéticos), teatro, dança, coral, brinquedoteca, jogos e/ou esportes, entre outras atividades socioeducativas. Nesse estudo, o lúdico é utilizado de forma a flexibilizar as relaçôes sociais entre os profissionais, como também com os usuários que buscam os serviços de saúde (MENDES; MEDEIROS, 2010).

Sobre a vivência com atividades lúdicas, foram promovidos com os alunos jogos de mímica, origami (técnica japonesa de dobrar papel), danças, entre outras. No que tange aos relatos dos alunos, destacamos o relatório B3:

A vivência de atividades lúdicas foi uma quebra de paradigmas, estávamos sendo iniciados em novas técnicas, mas não necessariamente práticas corporais precisam de uma formação, podem ser atividades simples e universais como dobraduras em papel ou mímicas, de forma que dificilmente se encontre empecilhos como espaço ou falta de um profissional 
ou equipamento especializado, sendo que é necessário frisar que tal atividade tem a capacidade de proporcionar a integração e a formação (B3).

No caso da hidroterapia, foi utilizado o espaço físico do Instituto Federal de Educação, Ciência e Tecnologia do Rio Grande do Norte (IFRN, Polo Caicó). De acordo com Resende, Rassi e Viana (2007), a hidroterapia é uma prática em meio líquido e auxilia na recuperação do equilíbrio e na prevenção de quedas em pessoas idosas. Para descrever essa prática, identificamos que, por ser em água:

[...] desacelera os movimentos e retarda a queda, o que prolonga o tempo para retomada da postura quando o corpo se desequilibra. A flutuação atua como suporte, o que aumenta a confiança do indivíduo e reduz o medo de cair. Assim, pode-se desafiar o indivíduo além de seus limites de estabilidade, sem temer as consequências de queda que podem ocorrer no solo (RESENDE; RASSI, VIANA, 2008, p. 62).

Tal prática vem sendo recorrida para tratar doenças ortopédicas, reumáticas e neurológicas (RESENDE; RASSI; VIANA, 2008) e foi utilizada de modo que os alunos pudessem vivenciar adaptaçóes ao meio aquoso, deslocamento do corpo, variaçōes de marcha e exercícios de equilíbrio. Para nossa vivência, a hidroterapia foi utilizada conjuntamente com atividades lúdicas, em duplas, com um ajudando o outro a flutuar e a encontrar seu centro de equilíbrio, com deslocamento na água, diferentes marchas e formas de nado.

A saber, essas foram as práticas vivenciadas e suas respectivas bases teóricas. Com elas, buscamos despertar o olhar para uma forma holística de cuidado, levando em consideração a ciência e, principalmente, as relaçôes socioculturais. Como podemos perceber nos relatórios:

As práticas corporais em saúde entram justamente nesse novo entendimento de corpo, isso porque muitas dessas práticas não atingem diretamente funções fisiológicas, mas trazem também outros benefícios para o indivíduo, como a inclusão em grupos sociais. Representam um outro mecanismo a ser utilizado na prevenção, promoção e tratamento em saúde (B5).

Hoje, vejo as práticas integrativas como uma necessidade, inclusive na atençâo básica, tendo em vista a gama de problemas que elas poderiam ser bastante resolutivas. [...] me fez perceber que as possibilidades terapêuticas ultrapassam a perspectiva da evidência e que a singularidade humana deve ser sempre colocada em primeiro plano, além de ser respeitada [...]. Hoje, as vejo não como integrativas, mas essenciais na conjuntura da saúde atual (A8).

Podendo pairar o campo da atividade física ou da atividade lúdica com o intuito de melhorar a saúde, em seu conceito amplo, abrangendo além do fisiológico, permeando a área psicológica, espiritual, cultural etc., e, consequentemente, melhorar a qualidade de vida (C6). 
O módulo promoveu uma espécie de desmistificação, uma vez que, relacionando os saberes, "os textos disponibilizados, como as práticas vivenciadas pelos próprios alunos, além das práticas direcionadas ao público, mostraram-se potencializadoras do cuidado, trazendo bem-estar, promovendo socialização e solidariedade" (B2), ou, como constatamos no relatório $\mathrm{C} 2$, "significando que será possível termos uma visão clínica ampliada sobre o indivíduo que procura o sistema de saúde, buscando sempre um tratamento holístico, isto é, que englobe a pessoa nos seus mais variados aspectos, e não apenas como uma doença”.

Desse modo, compreendemos que ainda há um trabalho a ser feito para a melhor compreensão de tais práticas nos serviços de saúde, "mesmo tendo em mente que isso ocorre não só pelo desconhecimento dos profissionais acerca dessas práticas, mas também pela não aceitação de parte da sociedade, a qual encara isso como não sendo medicina" (A4). É preciso discutir as práticas corporais e as práticas integrativas e complementares nos cursos de formação da Educação Física e de Medicina e seus impactos na saúde. Sendo percebidas como essenciais no quadro de saúde atual, elas representam possibilidades terapêuticas que "ultrapassam a perspectiva da evidência e que a singularidade humana deve ser sempre colocada em primeiro plano, além de ser respeitada" (A8).

Por fim, deixamos as indagações dos alunos para instigar novos diálogos:

E quando todos os exames aparentam bom estado de saúde e mesmo assim o paciente apresenta sinais claros de sofrimento? E quando as drogas mais potentes não são capazes de resolver o problema? Qual a decisão? Cruzar os braços e prestar um cuidado incompleto ou reconhecer que o problema pode ser visto por outro ângulo e praticar uma medicina mais preocupada com o ser humano doente que com a doença? Esses são questionamentos que disparam reflexôes (geradas graças à disciplina de Práticas Corporais) de extrema relevância para uma boa prática clínica $(\mathrm{C} 7)$.

\section{Consideraçóes finais}

Identificamos que os alunos se encontravam em uma confusão conceitual acerca das práticas corporais, atividades e exercícios físicos. Discutimos também sua potencialidade nos espaços da Atenção Básica, que passou a ser percebida como forma terapêutica cuja visão exige que seja holística, ou seja, que enxergue o ser humano de forma complexa, integrando as mais diversas esferas da vida.

Sob este aspecto, destacamos a necessidade da preparação dos alunos dos cursos de graduação, cujas áreas pertencem ao âmbito da Saúde, para o trabalho em equipes 
interdisciplinares e multidisciplinares, de modo a evitar a hierarquização entre todas essas profissóes e oferecerem um serviço que melhor compreenda a realidade das pessoas, sejam questóes sociais, biológicas, psicológicas, entre outras. Ao mesmo tempo, tal perspectiva de formação em equipes pode favorecer o relacionamento interprofissional e o reconhecimento da importância de cada uma dessas profissóes nos serviços em saúde. Em especial, na relação entre Educação Física e Medicina, é incontestável que a Educação Física tem em suas origens conhecimentos advindos da Medicina. Entretanto, vemos que nesta oportunidade se uniram para discutir sobre aspectos importantes da vida, do cotidiano, do afeto, do sofrimento, do adoecimento e até mesmo da morte, no que condiz às relaçóes sociais e os cuidados com a saúde.

Neste ínterim, devemos reconhecer que estamos em outros tempos e que ambos os campos de conhecimento e de atuação foram ampliados por perspectivas como a da interdisciplinaridade e da multiprofissionalidade, ou seja, assumindo uma postura de diálogo com outras áreas com vistas a promover conhecimentos mais complexos, mais condizentes à realidade e à dinâmica da vida, que comportem tanto a objetividade como a subjetividade.

Reconhecemos, portanto, que a formação interdisciplinar entre Educação Física e Medicina propiciou o conhecimento das práticas corporais, bem como a valorização de seus impactos na saúde da população, sendo necessário estarem cada vez mais presentes no sistema de saúde. Como pudemos perceber nos relatos, a Educação Física, nesta pesquisa, contribuiu para que os alunos de Medicina da EMCM compreendessem os benefícios das diversas práticas corporais, validassem sua necessidade para a comunidade e assumissem uma postura que corrobora para o diálogo entre as áreas de saúde, oportunizando práticas de cuidado mais qualificadas e adequadas à realidade biopsicossocial de cada um e permitindo experienciar o próprio corpo e o corpo do outro.

Ressaltamos ainda a importância de cursos de formação em Medicina como este promovido pela EMCM em razão de sua faceta de interiorização e imersão na comunidade com um forte trabalho voltado ao (re)conhecimento das diversas redes de atenção, em especial, a atenção primária à saúde, sem negligenciar, em momento algum, a formação médica para grandes centros e demais espaços de atuação pertinentes a estes profissionais. É necessário reconhecer o esforço de todos(as) os(as) profissionais e corpo docente que fazem a instituição e a formação acontecerem da melhor maneira possível. 
Por fim, utilizamos este espaço para expressar a importância em defender espaços públicos de formação e de saúde, de maneira articulada, como as universidades públicas e as redes de atenção à saúde, e em manter a luta contra qualquer desmonte do SUS e das equipes que nele exerciam um papel fundamental em inúmeras comunidades como o NASF-AB. ${ }^{1}$

\section{Referências}

BARDIN, L. Análise de conteúdo. Lisboa: Ediçōes 70, 2011.

BARROS, N. F. et al. Yoga e promoção da saúde. Ciência \& Saúde Coletiva, v. 19, n. 4, p. 13051314, 2014.

BRASIL. Senado Federal. Constituição Da República Federativa do Brasil. Brasília-DF: Presidência da República: Centro Gráfico, 1988.

Lei no 8.080 , de 19 de setembro de 1990. Dispóe sobre as condições para a promoção, proteção e recuperação da saúde, a organização e o funcionamento dos serviços correspondentes e dá outras providências. Diário Oficial da União 1990, 19 set.

. Ministério da Saúde. Coordenação de Doenças Crônico-Degenerativas. Orientaçôes básicas sobre atividade física e saúde para profissionais das áreas de Educação e de Saúde. Brasília: Ministério da Saúde, Ministério da Educação e do Desporto, 1995.

- Ministério da Saúde. Glossário temático: práticas integrativas e complementares em saúde. Brasília: Ministério da Saúde, 2018.

- Ministério da Saúde. Política Nacional de Práticas Integrativas e Complementares no SUS - PNPIC-SUS. Brasília: Ministério da Saúde, 2006b.

. Ministério da Saúde. Política Nacional de Promoção da Saúde. Portaria no 687 MS/ GM, de 30 de março de 2006. Aprova a Política de Promoção da Saúde. Diário Oficial da União, 2006a.

- Ministério da Saúde. Portaria no 154 de 24 de janeiro de 2008. Cria os Núcleos de Apoio à Saúde da Família - NASF. Diário Oficial da União, 2008.

. Ministério da Saúde. Portaria no 719, de 7 de abril de 2011. Institui a criação do programa academia da saúde no âmbito do sistema único de saúde. Diário Oficial da União, Brasília, 2011.

- Ministério da Saúde. Secretaria de Assistência à Saúde. Coordenação de Saúde da Comunidade. Saúde da Família: uma estratégia para a reorientaçâo do modelo assistencial. Brasília: Ministério da Saúde, 1997.

CARMO JÚNIOR, W. Educação Física e a Cultura: uma ontologia das práticas corporais. Motriz, v. 5, n. 1, Junho, 1999. 
CONSELHO NACIONAL DE SAÚDE (CNS). Regulamentação das profissóes de Saúde, Resolução no 218/97, Diário Oficial da União, 1997. Disponível em: <http://www. saudeemmovimento.com.br/conteudos/conteudo_print.asp?cod_noticia=193>.

CUNHA, A. A. Ventosaterapia. São Paulo: Ícone, 1996.

ESCOLA MULTICAMPI DE CIÊNCIAS MÉDICAS DO RIO GRANDE DO NORTE (EMCM). Missão da EMCM. Disponível em: <http://emcm.ufrn.br/index.php>. Acesso em: 17 ago. 2018.

FRAGA. A. B. Exercício da informação: governo dos corpos no mercado da vida ativa. Campinas: Autores Associados, 2006.

GEOFFROY, C. Alongamento para todos. São Paulo: Manole, 2001.

GIL, A. C. Como elaborar projetos de pesquisa. 4 ed. São Paulo: Atlas, 2002.

GUEDES, D. P. Atividade física, aptidão física e saúde. In: BRASIL. Ministério da Saúde. Coordenação de doenças crônico degenerativas. Orientaçôes básicas sobre atividade física e saúde para profissionais das áreas de Educação e de Saúde. Brasília: Ministério da Saúde, Ministério da Educação e do Desporto, 1995.

INSTITUTO BRASILEIRO DE GEOGRAFIA E ESTATÍSTICA [Internet]. Caicó. Rio de Janeiro: IBGE, 2010. Disponível em: <https://cidades.ibge.gov.br/brasil/rn/caico/pesquisa/23/2 7652?detalhes=true $>$. Acesso em: 30 jul. 2019.

KASAI, J. Y. T. et al. Efeitos da prática de Tai Chi Chuan na cognição de idosas com comprometimento cognitivo leve. Einstein. v. 8, n. 1, p. 40-45, 2010.

KIM, D. S. Suma de Diagnósticos Secretos para Tratamentos com Ventosaterapia. Dong Yang, 2002. MANTOVANI, E. P.; FORTI, V. A. M. Epidemiologia, atividade física e saúde. In: VILARTA, R (Org.). Saúde Coletiva e Educação Física: conceitos e aplicaçôes dirigidos à graduação em educação física. Campinas: IPES Editorial, 2007.

MATTOS, R. A. Princípios do Sistema Único de Saúde (SUS) e a humanização das práticas de saúde. Interface - Comunic., Saude, Educ. Botucatu, v. 13, supl. 1, p. 771-80, 2009.

MELO, C. K.; ANTUNES, P. C.; SCHNEIDER, M. D. Desenferrujando dobradiças: as práticas corporais na maturidade. In: SILVA, A. M.; DAMIANI, I. R. (Orgs.). Práticas corporais. Florianópolis: Nauemblu Ciência \& Arte, 2005, vol. 3.

MELO, C. K.; SCHNEIDER, M. D. ANTUNES, P. C. O corpo respir-ação na busca do equilíbrio da vida: elementos para uma (re)significação das práticas corporais. In: SILVA, A. M.; DAMIANI, I. R. (Orgs.) Práticas corporais. Florianópolis: Nauemblu Ciência \& Arte, 2006.

MELO, L. P. et al. A Escola Multicampi de Ciências Médicas da Universidade Federal do Rio Grande do Norte, Brasil, no contexto do Programa Mais Médicos: desafios e potencialidades. Interface-Comunic., Saude, Educ. Botucatu, v. 21, supl. 1, p. 1333-1343, ago. 2017. 
MENDES, I. A. C. Desenvolvimento e saúde: a declaração de Alma-Ata e movimentos posteriores. Rev. Latino-Am. Enfermagem, v. 12, n. 3, maio-jun. 2004.

MENDES, M. I. B. S.; MEDEIROS, L. P. O Programa Saúde da Família em Natal e as atividades lúdicas. In: MENDES, M. I. B. S.; OLIVEIRA, M. V. F. (Orgs.). Cenários lúdicos em unidades de saúde da família. Natal: IFRN, 2010.

MINAYO, M. C. de S. (Org.). Pesquisa social: teoria, método e criatividade. Petrópolis, RJ: Vozes, 2009.

OLIVEIRA, G. Doenças crônico-degenerativas: hipertensão arterial sistêmica. In: VILARTA, R. (Org.). Saúde Coletiva e Educaçâo Física: conceitos e aplicaçôes dirigidos à graduação em educação física. Campinas: IPES Editorial, 2007.

ORGANIZAÇÃO MUNDIAL DA SAÚDE. Carta de Ottawa para a promoção da saúde. Geneva: OMS, 1986.

PAIM, J. et al. The Brazilian health system: history, advances, and challenges. The Lancet, v. 377, n. 9779, p. 1778-1797, 2011.

PINHEIRO, C. H. J. et al. Uso do ioga como recurso não-farmacológico no tratamento da hipertensão arterial essencial. Revista Brasileira de Hipertensão, v. 14, n. 4, p. 226-232, 2007.

RESENDE, S. M.; RASSI, C. M.; VIANA, F. P. Efeitos da hidroterapia na recuperação do equilíbrio e prevenção de quedas em idosas. Revista Brasileira de Fisioterapia, v. 12, n. 1, p. 5763, jan-fev. 2008.

RIO GRANDE DO NORTE. Secretaria do Estado da Saúde Pública. Portaria no 274/GS, de 27 de junho de 2011. Aprova a Política Estadual de Práticas Integrativas e Complementares (PEPIC) no Sistema Único de Saúde do RN. Diário Oficial do Estado. Natal, 2011. Disponível em: <http://www.redehumanizasus.net/sites/default/files/portaria_no_274gs_-sesap_-_pepic_ doe_28_de_junho_20111.pdf>. Acesso em: 30 jul. 2019.

SANTOS, J. B.; SILVA, J. A. B. Terapia através da massagem: massoterapia no centro de atenção psicossocial de Amargosa/BA. Revista Acadêmica GUETO, v. 1, n.1, p. 120-134, 2015.

SILVA, J. G. S. Efeitos fisiológicos da atividade física. In: BRASIL. Ministério da Saúde. Coordenação de doenças crônico degenerativas. Orientaçôes básicas sobre atividade física e saúde para profissionais das áreas de Educação e de Saúde. Brasília: Ministério da Saúde, Ministério da Educação e do Desporto, 1995.

SISTEMA ÚNICO DE SAÚDE. Disponível em: <http://www.saude.gov.br/sistema-unico-desaude>. Acesso em: 8 ago. 2019.

TACCOLINI, M. Manual de Hatha Yoga: 108 asanas: métodos práticos. Disponível em: <http://www.yoganataraja.com.br/Livros/YogaNatarajaAsana/108familias.html>. Acesso em: 30 jul. 2019. 
VIANA, A. L. D.; DAL POZ, M. R. A Reforma do Sistema de Saúde no Brasil e o Programa de Saúde da Família. Physis Rev. Saúde Coletiva. Rio de Janeiro, v. 15, supl. 1, p. 225-264, 2005. VILARTA, R (Org.). Saúde Coletiva e Educaçâo Física: conceitos e aplicaçôes dirigidos à graduação em educação física. Campinas: IPES Editorial, 2007.

\section{Nota}

${ }^{1}$ M. A. Franco: coleta e análise de dados, revisão bibliográfica, redação e revisão do artigo. L. P. da Silva: curadoria de dados, análise formal, pesquisa, metodologia, redaçáo do artigo. J. D. Rodrigues: análise formal, pesquisa, redação do artigo. M. de O. Aguiar: análise formal, pesquisa, redação e revisão do artigo. M. I. B. de S. Mendes e I. de O. Caminha: análise formal, pesquisa, administraçáo do projeto, redação e revisão do artigo. 


\section{Abstract}

Body practices in health promotion and

quality of life: acting between Physical

Education and Medicine at the Multicampi

School of Medical Sciences of Rio Grande do

Norte state, Brazil

This article aims to identify the understanding of the

body practices of medical students at the Multicampi School of Medical Sciences of Rio Grande do Norte,

Brazil, and discuss their realization in the context of

Primary Healthcare. Through a documental research with a qualitative approach, we analyzed the 47 final reports of the discipline Body Practices in the promotion of health and quality of life, which took place in the 2017-1, 2017-2 and 2018-1 periods. Through document analysis, it was possible to identify how the students understood the body and health, at the same time that experiences were promoted that helped students to overcome prejudices about the practices, highlighting their importance in the field of health, especially which is consistent with an expanded medical training, acting in Primary Care, in order to be able to experience their own bodies and that of others.

> Keywords: Physical Education; Medicine; body practices; health; Primary Healthcare. 